\title{
Coulisses
}

Revue de théâtre

14 | Printemps 1996

Varia

\section{À propos des Phéniciennes d'Euripide}

Atelier du DUMST - Mise en scène Jean-Michel Potiron

\section{Romain Duhoux}

\section{OpenEdition}

\section{Journals}

Édition électronique

URL : http://journals.openedition.org/coulisses/4758

DOI : $10.4000 /$ coulisses.4758

ISSN : 2546-9460

Éditeur

Presses universitaires de Franche-Comté

\section{Édition imprimée}

Date de publication : 1 mai 1996

Pagination : 63

ISSN : $1150-594 X$

\section{Référence électronique}

Romain Duhoux, «À propos des Phéniciennes d'Euripide », Coulisses [En ligne], 14 | Printemps 1996, mis en ligne le 20 mars 2019, consulté le 30 octobre 2019. URL : http://journals.openedition.org/ coulisses/4758; DOI : 10.4000/coulisses.4758

Ce document a été généré automatiquement le 30 octobre 2019

Coulisses 


\title{
À propos des Phéniciennes d'Euripide
}

\author{
Atelier du DUMST - Mise en scène Jean-Michel Potiron
}

\author{
Romain Duhoux
}

1 Pour parvenir à toucher un texte aussi dense que Les Phéniciennes d'Euripide, en l'espace d'un mois, nous avons eu recours à une approche particulière, englobant l'improvisation et la consolidation d'un groupe, existant déjà en partie, qui nous a permis d'économiser du temps sans que la qualité s'en ressente.

La première semaine a exclusivement été consacrée à une improvisation singulière : chaque acteur a interprété chaque personnage, sans distinction de sexe.

Cette première approche nous a permis de nous confronter aux motivations profondes de chacun des personnages et, par conséquent, d'explorer de l'intérieur les relations entre ceux-ci.

De plus, l'improvisation évite de cloisonner le personnage dans l'univers formel du «tragique ».

2 La mise en dérision du personnage permet d'aborder le texte avec une relative légèreté, d'ouvrir des chemins pour accéder au côté humain, donc intérieur, des personnages. On évite ainsi le plaquage systématique d'attitudes extérieures, conventionnelles du héros tragique.

J.M. Potiron a posé comme principe de base : le chœur / personnage principal.

Pour accéder à une unité dans le chœur qui ne soit pas artificielle, il fallait consolider les relations de notre groupe de travail au point qu'elles transparaissent sur scène, sans pour autant nier les individus.

Les échauffements visaient tout spécialement, de manière tout à fait tacite, à lier les comédiens entre eux.

En effet, la fatigue physique, parfois même la souffrance, nous réunissaient dans la même difficulté.

Les échauffements étaient donc destinés d'abord à nous préparer physiquement avant le travail proprement dit, mais surtout à nous rassembler dans une même énergie, vers un objectif commun.

3 Ce chœur antique nous place, malgré les apparences, face à une actualité brûlante et parfois gênante. 
En effet, les Phéniciennes, cousines des Thébains, sont à la fois étrangères à la cité par la nationalité et membre de la cité par le sang, elles sont otages et pourtant consentent à souffrir avec ceux qui les retiennent, encore au nom du sang.

Ces ambivalences font de ce chœur un être singulier parmi les chœurs grecs, traditionnellement formés de membres de la cité.

4 Ici, elles sont et, en même temps, ne sont pas. Elles n'agissent pas, mais observent et commentent. Elles sont à la fois objectives, de par leur regards extérieurs, et subjectives de par leur souffrance solidaire.

Elles sont à la fois non-thébaines et thébaines, tout cela parce que phéniciennes.

Bref, elles sont ce regard extérieur et impuissant à ce qui se déroule devant elles.

On pourrait aisément comparer Thèbes à la Bosnie ou au Rwanda et les Phéniciennes aux casques bleus de l'ONU. Ce qui nous plonge aussi dans l'actualité, c'est le traitement comique qu'a appliqué J.M. Potiron à certaines scènes du milieu de la pièce.

Cela a pour effet de rendre l'ensemble de la pièce beaucoup plus tragique. En effet, si l'on ne montre que du tragique aux informations télévisées comme au théâtre, le téléspectateur comme le public s'habitue et, à force, ne voit plus ce qu'on lui montre. Ici, l'action est d'abord tragique, puis drôle, ce qui a pour effet de détendre le public, puis plus tragique encore. Le tragique est ainsi relativisé, il ne se noie plus dans l'ensemble, mais s'installe à des places stratégiques.

6 Le travail sur Les Phéniciennes nous a appris, je pense, à relativiser notre individualité au sein d'une création commune.

Nous ne nous sommes pas placés en tant que second, premier rôle ou dans une quelconque hiérarchie narcissique. Chacun avait tout simplement trouvé sa place au sein d'un tout.

\section{AUTEURS}

ROMAIN DUHOUX

Étudiant DUMST 